\title{
Correlating Substrate Properties with Pressure Sensitive Adhesive Performance
}

$\underline{\text { Terri Powell }}{ }^{1}$, Michaeleen Pacholski $^{1}$, Bill Griffith $^{2}$, and Dave Keely ${ }^{3}$

1. The Dow Chemical Company, Analytical Sciences, Collegeville, PA, USA.

2. The Dow Chemical Company, Functional Materials, Collegeville, PA, USA.

3. The Dow Chemical Company, Functional Materials, Louisville, KY, USA.

Pressure sensitive adhesive (PSA) performance is influenced by both the properties of the adhesive and the properties of the substrate. For bonding, the most important properties of the substrate are surface roughness and surface chemistry. The most common methods to test for adhesive performance are peel, shear, and tack. Shear is most sensitive to the bulk properties, while peel and tack are more strongly affected by interactions between the substrate and the adhesive.

For this investigation, common substrates were peel tested and then analyzed to correlate the surface chemistry and surface roughness with performance. Surface chemistry measurements were made with secondary ion mass spectrometry (SIMS), which provides information about the molecular and elemental chemistry in the top $2 \mathrm{~nm}$ and X-ray photoelectron spectroscopy (XPS), which yields quantitative elemental and chemical state information from the top $10 \mathrm{~nm}$. Optical profilometry, or white light interferometry, was used to look at surface roughness, with scanning electron microscopy (SEM) providing supplemental information about surface texture.

HDPE bottles were examined. These samples have visually different surface textures (Figure 1), which are confirmed as differences in surface roughness by the optical profilometry data. However, there is no obvious correlation between the surface roughness and the peel values. (Table 1.) Typically, the surface chemistry of HDPE shows only $\mathrm{C}$ and $\mathrm{O}$ and possibly low levels of $\mathrm{P}$ from antioxidants. In this case, both the jug and the tan bottle also have N, Na, S, and $\mathrm{Si}$ at the surface. (Table 2.) Examination by SIMS shows the presence of polydimethyl siloxane (silicone) and lauryl sulfate on the surfaces of these two samples, both of which can negatively impact adhesion. The absence of these contaminants on the flame treated sample is consistent with the higher peel value.

Corrugated cardboard with different amounts of recycled material was also analyzed. The peel values are much lower for the $100 \%$ recycled cardboard, but the surface chemistry by XPS is similar. SEM images show that the $40 \%$ and $85 \%$ recycled samples have a similar appearance, with well adhered fibers and little organic material. The $100 \%$ recycled sample is not as smooth, and has loose fibers sticking up from the surface. (Figure 2.) This sample also has inorganic material present, which EDS shows to be Al, Ca, and Si. Optical profilometry confirms the observations made from the SEM images. The roughness values for the $40 \%$ and $85 \%$ samples are similar, while the $100 \%$ sample is significantly rougher. (Table 3.) For these samples, the differences in adhesion are likely due to higher surface roughness and loose fibers, and not related to surface chemistry.

In conclusion, it is important to consider the adhesion data and the analytical data together to determine the factors most important to adhesive performance. For the HDPE samples, visibly different surface roughness was not relevant to adhesion, but differences in surface chemistry correlate with differences in peel. For the corrugated cardboard samples, there was no obvious difference in surface chemistry, but differences in roughness and morphology indicate why performance varies. 


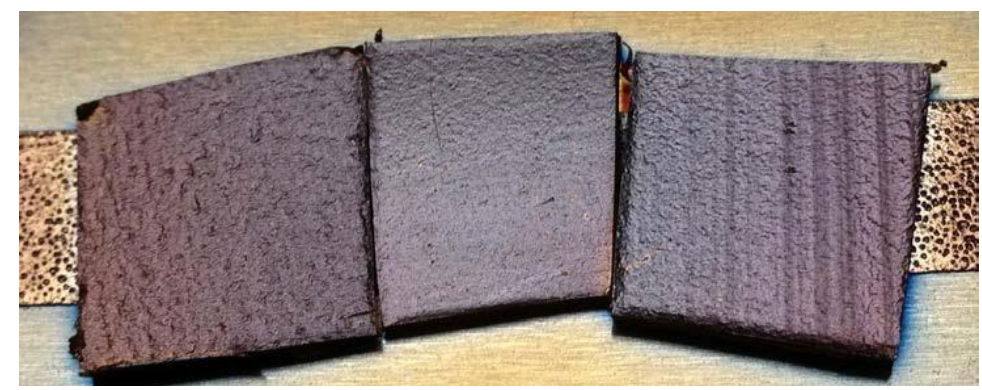

Figure 1: $\mathrm{Au} / \mathrm{Pd}$ coated HDPE bottles, showing differences in surface texture.

From left to right: jug, tan bottle, and flame treated.

\begin{tabular}{|c|c|c|c|}
\hline Sample & $\begin{array}{c}\text { PSA Peel } \\
\text { (oz/in) }\end{array}$ & $\begin{array}{c}\mathrm{Ra}(\mathrm{mm}) \\
\text { w/(StDev) }\end{array}$ & $\begin{array}{c}\mathrm{Rq}(\mathrm{mm}) \\
\text { w/StDev }\end{array}$ \\
\hline Jug & 8.7 & $4.8(0.7)$ & $6.4(1.4)$ \\
\hline Tan Bottle & 5.7 & $1.7(0.3)$ & $2.2(0.3)$ \\
\hline Flame Treated & 17.4 & $2.4(0.4)$ & $3.1(0.5)$ \\
\hline
\end{tabular}

Table 1: Peel and Surface Roughness Data for HDPE samples, where Ra is the average roughness and $\mathrm{Rq}$ is the root mean square roughness.

\begin{tabular}{|c|c|c|c|c|c|c|}
\hline Sample & $\mathrm{C}$ & $\mathrm{N}$ & $\mathrm{Na}$ & $\mathrm{O}$ & $\mathrm{S}$ & $\mathrm{Si}$ \\
\hline Jug & $93.2(1.0)$ & $0.3(0.1)$ & $0.3(0.1)$ & $4.6(0.7)$ & $0.2(0.1)$ & $1.2(0.1)$ \\
\hline Tan Bottle & $89.0(2.0)$ & $0.4(0.3)$ & $0.4(0.2)$ & $8.0(1.0)$ & $0.2(0.1)$ & $1.8(0.3)$ \\
\hline Flame Treated & $89.6(0.9)$ & $0.5(0.3)$ & & $9.9(0.6)$ & & \\
\hline
\end{tabular}

Table 2: Average XPS Data in atomic \% (and standard deviations) for HDPE samples.
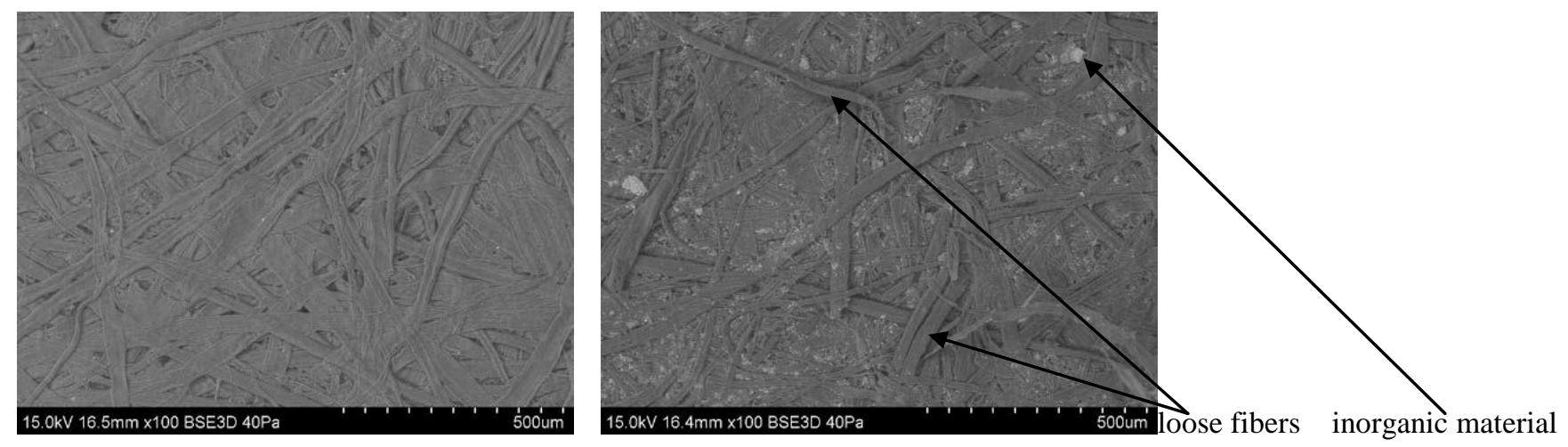

Figure 2: SEM Images of Corrugated Cardboard with $40 \%$ recycled content (left) and 100\% recycled content (right). Note the loose fibers and inorganic material present in the $100 \%$ recycled cardboard.

\begin{tabular}{|c|c|c|c|}
\hline Sample & Peel (oz/in) & $\begin{array}{c}\mathrm{Ra}(\mathrm{mm}) \\
\text { w/(StDev) }\end{array}$ & $\begin{array}{c}\mathrm{Rq}(\mathrm{mm}) \\
\text { w/StDev }\end{array}$ \\
\hline $40 \%$ recycled & 22.9 & $6.6(1.0)$ & $8.2(1.3)$ \\
\hline $85 \%$ recycled & 22.3 & $6.2(0.6)$ & $7.7(0.7)$ \\
\hline $100 \%$ recycled & 6.8 & $8.7(0.5)$ & $10.7(0.5)$ \\
\hline
\end{tabular}

Table 3: Peel and Surface Roughness for Corrugated Cardboard Samples. 